\title{
РЕЦЕНЗИИ
}

УДК $572+930.23$

DOI: $10.33876 / 2311-0546 / 2021-54-2 / 373-379$

(C) M.M. Герасимова

\section{РЕЦЕНЗИЯ НА: ЗУБОВА А.В., МОИСЕЕВ В.Г., КУЛЬКОВ А.М., ОБОДОВСКИЙ А.В. НОВЫЕ РЕЗУЛЬТАТЫ ИЗУЧЕНИЯ КРАНИОЛОГИЧЕСКИХ И ОДОНТОЛОГИЧЕСКИХ МАТЕРИАЛОВ ВЕРХНЕПАЛЕОЛИТИЧЕСКОЙ СТОЯНКИ КОСТЕНКИ 15 // CAMERA PRAEHISTORICA, 2020. 2 (5): 147-155*}

Ссылка при цитировании: Герасимова М.М. Рецензия на: Зубова А.В., Моисеев В.Г., Кульков А.М., Ободовский А.В. Новые результаты изучения краниологических и одонтологических материалов верхнепалеолитической стоянки Костенки 15 // Camera praehistorica, 2020. № 2 (5): 147-155 // Вестник антропологии, 2021. № 2. С. 373-379.

Опубликованная в конце 2020 г. статья группы исследователей из Петербурга (3yбова, Моисеев и дp. 2020) о новых результатах краниологических и одонтологических исследований материалов верхнепалеолитической стоянки городцовской культуры Костенки 15 не могла не вызвать интереса и пристального внимания коллег. Возникло предположение, что были найдены ранее не обнаруженные фрагменты, помимо участвовавших в реконструкции сильно фрагментированного черепа (перечисление того, что было найдено, приведено в Каталоге верхнепалеолитических находок МАЭ, № коллекции 6109). В далеких 50-ых годах прошлого века было сделано все возможное для того, чтобы эта находка и спустя почти 70 лет могла послужить объектом современных исследований. Авторами «ремейка» старых находок, весьма похвального, поскольку в их арсенале новые методы исследования, прежде всего, была сделана ревизия предложенной когда-то реконструкции черепа из Костенок-15. Гипотетичность реставрации и неточность измерительных признаков черепа были отмечены самим автором исследования, который приводил метрические данные с вопросом или даже двумя (Якимов 1957). Эта гипотетичность метрических характеристик была отмечена и позднее, при повторном исследовании этой находки (Герасимова 1982). Однако, метрические характеристики черепа из погребения на стоянке Костенки-15 (далее К-15) и их соотношения в ряду других детских и подростковых черепов верхнего палеолита Европы, отнюдь не выпадают из этого ряда (см. напр.: Алексеев 1978). Эта, еще одна, попытка ревизии была предпринята с целью доказать, что метрические характеристики реставрированного черепа категорически не могут быть использованы не просто для каких-либо вы-

Герасимова Маргарита Михаайловна - к.и.н., ведущий научный сотрудник, Институт этнологии и антропологии РАН (Москва, Ленинский пр. 32-а) Эл. почта: gerasimova.margarita@gmail.com

* Публикуется в соответствии с планом научно-исследовательских работ Института этнологии и антропологии РАН 
водов, а конкретно - для доказательства, выдвинутого В.П. Якимовым предположения о сходстве метрических данных и контуров мозговой коробки черепа К-15 и черепов Пржедмости (Пшедмост) II и XXII. Предположение о сходстве с моравскими черепами черепов К-15 и К-14 (с. Костенки, правобережье Среднего Дона, около 60 стоянок и 5 погребений / палеоантропологических находок различной культурно-хронологической атрибуции) позволило В.П. Якимову в свое время выделить крайне полиморфный тип «восточных кроманьонцев». Идея эта в настоящее время достаточно устарела, новые данные о разнице в абсолютном возрасте этих находок и неясность культурной принадлежности погребения К-14 против этой гипотезы. К тому же сама идея о морфологических вариантах европейского верхнепалеолитического населения, не подкрепленная географическим критерием, давно потеряла научную значимость в связи с вошедшим в арсенал современных представлений понятия о полиморфизме верхнепалеолитического населения и популяционного подхода к изучению изменчивости. Так или иначе, но авторы статьи поставили себе цель показать отличие антропологической находки К-15 от находок, ассоциируемыми ими с граветтскими палеоантропологическими находками. Неточность реконструкции черепа должна была продемонстрировать таблица с измерениями В.П. Якимова и оценкой положения краниометрических точек, между которыми должны быть взяты размеры. Придется разочаровать авторов статьи, приведенная таблица не отвечает поставленной цели: в таблицу, должную показать неточность краниометрических характеристик реставрированного черепа К-15, вкрались трудно объяснимые чудовищные ошибки. Я позволила себе сделать выкопировку из таблицы размеров, приведенных А.В. Зубовой с соавторами, и сравнить их с размерами, опубликованными В.П. Якимовым: 9 из 20 размеров не соответствовали данным В.П. Якимова. Кроме того, приведенные авторами статьи метрические характеристики просто абсурдны. Даже не будучи краниологом, трудно не заметить этого, т. к. хорды не могут быть больше дуг, часть дуги не может быть больше целой, затылок шире поперечного диаметра и т.д. (см. ниже приведенную таблицу 1).

Таблица 1

Метрические характеристики черепа К-15 (Якимов 1957 и Зубова и др. 2020)

\begin{tabular}{|c|c|c|}
\hline № по Мартину & Якимов & Зубова \\
\hline 12. Ширина затылка & $99 ?$ & 132 \\
\hline 24. Поперечная дуга & 298 & 112 \\
\hline 25. Сагиттальная дуга & $380^{*}$ & 106 \\
\hline 26. Лобная дуга & 126 & $66^{* *}$ \\
\hline 27. Теменная дуга & 137 & $89 * *$ \\
\hline 28. Затылочная дуга & 117 & 109 \\
\hline 29.Лобная хорда & 106 & $104 * *$ \\
\hline 30. Теменная хорда & 124 & $135^{* *}$ \\
\hline 43. Верхняя ширина лица & 87 & 113 \\
\hline
\end{tabular}

- №25 =№26+№27+№28. ** дуги меньше хорд 
Неискушенный читатель мог предположить, что применение новых методов, в частности - компьютерной томографии, позволит создать новую виртуальную реконструкцию из сохранившихся фрагментов, но ее применение, судя по приведенной иллюстрации, только позволило удалить восковую мастику, заменявшую отсутствующие фрагменты и закрепляющую положение сохранившихся относительно друг друга. Не более того. Несмотря на новые открывшиеся возможности компьютерной томографии никакой новой построенной виртуальной реконструкции черепа предложено не было, вопреки утверждению авторов статьи. Опубликованные мелкомасштабные томограммы черепа в непонятных нормах маловыразительны и неинформативны. Поэтому из названия статьи вполне обоснованно могут быть удалены слова «новые краниологические».

Остановимся на рассмотрении новых одонтологических материалов, полученных в результате компьютерной томографии, и открывшихся новых возможностей:

1. Компьютерная томография позволила описать более детально характеристики зубной системы индивида К-15, в частности было выявлено состояние корневой системы, что позволило уточнить возраст ребенка из Костенок-15, который теперь был определен не в 6-7 лет, а в 5 .

2. Компьютерная томография позволила выявить ошибку в реставрации: правый и левый верхние постоянные моляры были перепутаны местами и развернуты на 90 градусов

3. В результате томографии увеличилось число одонтологических образцов, доступных для изучения. К сожалению, анонсированное обследование непрорезавшихся постоянных зубов по обширной программе, включающей около 30 метрических и описательных признаков, в настоящей статье не получило освещения.

4. Виртуальная томография позволила детально изучить морфологию постоянных первых нижних и верхних моляров индивида К-15.

Авторы ограничились сравнительным анализом метрических характеристик (VL и MD диаметрами коронок) первых верхних и нижних постоянных моляров и кратким морфологическим описанием их коронок, и коронок латеральных верхних резцов, чему и посвящена рецензируемая статья. На латеральных верхних резцах диагностируется лопатообразность, выраженность которой 2 балла. Далее, вместо обещанной обширной программы исследования - краткая констатация: отсутствие редуцированности верхних первых моляров, присутствие элементов задней ямки, бугорка Корабелли на обоих зубах и нейтральность одонтоглифического узора. Непонятно, нейтральность по отношению к чему? Далее авторы отмечают, что нижние первые моляры- четырехбугорковые, что является выраженным европеоидным и прогрессивным признаком. Одонтоглифический узор первых нижних моляров дан более подробно: «вторая борозда метаконида впадает в фиссуру III, тип соотношения точек впадения первых борозд метаконида и протоконида - 3». Одонтоглифический узор демонстрирует некоторое уклонение в «восточном» направлении» (с. 151) .«В особенностях постоянных верхних резцов и нижних моляров был выявлен противоречивый комплекс признаков, свидетельствующий о наличие в составе носителей городцовской культуры как западного комплекса, маркируемого 4-бугорковыми первыми нижними молярами, так и восточного компонента, о чем говорит лопатообразность верхних латеральных резцов и одонтоглифический узор первых нижних моляров» (с. 152). Восточный компонент воспринимается авторами статьи, 
как привнесенный из Азии, вся огромная территория которой в статье представлена младенцами из погребения на стоянке Мальта (Восточная Сибирь, Прибайкалье).

Далее авторы развивают эту идею, считая, что результаты сравнения размерных признаков коронок верхних и нижних первых моляров также показывают специфичность индивида К-15 не только относительно граветтских форм, но и в проявлении восточного импульса в общем верхнепалеолитическом популяционном континууме (Рис.4 и 5). Однако, приведенные авторами рецензируемой статьи сравнительные материалы для бивариантных графиков организованы отнюдь не по популяционному принципу, а в рамках, как замечено в статье, историко-хронологических срезов, а скорее даже технологических комплексов: ориньяк, граветт, мадлен. Непонятно только, для чего в группу сравнительных материалов была введена северо-африканская серия из Тафоральта (голоценового времени). Можно было бы сказать, что материал организован в рамках археологических культур, если бы в группу граветтских памятников не были бы включены материалы из Сунгиря (сунгирская культура), из Костенок 18 (костенковско-авдеевская культура), моравские находки, относящиеся к так наз. «восточному граветту». Авторы статьи пишут, что в бивариантных графиках анализировались данные, как по отдельным индивидам, так и серийный материал. Где-то указывая конкретно, что это данные по двум индивидам, как для португальских находок из Лагар Велью, а где-то нет. Так, например, непонятно, о каком Сунгире идет речь. Какой Сунгирь, 2 или 3? Или это суммарная характеристика? А.А. Зубов, исследовавший их, подчеркивал, что «различия между ними очень отчетливы и характерны: по вестибуло-лингвальному диаметру всех зубов С2 превосходит С3» (Зубов 1984: 163). Точно такие же претензии можно предъявить авторам статьи, когда они не указывают, какая из шести находок из Грота Детей (Гримальди), относящихся к граветту или эпиграветту и датируемых с разницей в 10 тыс. лет, участвует в анализе. Эти претензии можно продолжить относительно находок и в Абри-Пато (речь идет об индивиде Пато 1 или выборке, принадлежащей нескольким индивидам?), и в Пайличчи или Арен Кандиде, содержащих находки, также относящиеся к разным периодам. И эти претензии не являются надуманными, поскольку именно на рубеже граветта и эпиграветта, т.е. рубеже средней поры верхнего палеолита и поздней, произошли наиболее значительные редукционные изменения в процессе морфологической одонтологической сапиентации.

Так или иначе, приведенные бивариантные графики, и многомерное шкалирование, и эвклидовы расстояния показали отдельное положение индивида К-15 от тесной совокупности, к которой кроме граветтских и восточнограветтских находок, как уже мной было отмечено, авторы посчитали возможным отнести и К-18 и Сунгирь. Очень интересным оказалось положение серии со стоянки Павлов (восточный граветт), так и оказавшееся без всяких комментариев. Так же как зафиксированное сходство К-15 с ориньякской серией из Ла-Балозьер, сходство с которой «отмечается и по неметрическим признакам» (с. 153). Правда, не указано, каким. Об этом ни слова, это остается загадкой.

Итак, одна из задач, поставленных в рецензируемой статье, была решена: ни краниологические, ни метрические одонтологические данные не свидетельствуют о сходстве индивида К-15 с моравскими и вообще с граветтскими находками. В сущности, в этом утверждении нет ничего необычного или неожиданного. А почему, собственно говоря, эта находка должна входить в круг форм, связанных с моравски- 
ми и итальянскими памятниками, относящимися к граветту? Знакомство с археологической литературой говорит о том, что из костенковских стоянок только второй слой стоянки Костенки-8 обнаруживает некоторые аналогии с восточным граветтом (см. работы А.Н. Рогачева 50-ых годов прошлого века и новейшие-А.А. Синицына).

Вторым выводом, пожалуй, самым значительным, из анализа бивариантных графиков, было то, что граветские серии образуют довольно компактное расположение относительно друг друга, а индивид из К-15 находится на значительном расстоянии от них, обнаруживая некоторое промежуточное положение между граветскими памятниками и Мальтой. И это обстоятельство, наряду с морфологическими особенностями коронки первого нижнего постоянного моляра К-15 и верхнего латерального резца, по мнению А.В. Зубовой, подтверждает наличие восточного компонента. Ребенок из погребения на стоянке Мальта, расположенной далеко на восток, должен, по мнению авторов статьи, быть носителем этого восточного компонента. Но, увы! незнание литературы сыграло с авторами статьи дурную шутку. Дело в том, что вопреки географическому положению одонтологическая характеристика индивида из Мальты (Мальта 2) прямо противоположна ожидаемой: «зубы ребенка Мальта 2 имеют выраженный западный комплекс особенностей, среди которых (помимо отсутствия лопатообразной формы резцов, шестого бугорка, дистального гребня тригонида, коленчатой складки) имеется такой яркий одонтоглифический показатель, как тип «ІІ» борозды 2 med на первых постоянных нижних молярах, что можно было бы назвать ультразападной чертой. Одонтологический тип детей из Мальты характеризуется почти современным типом зубной системы в его «западном» европеоидном варианте» (Зубов, Гохман 2003; циит. по: Зубов 2019:372).

Заканчивая свою рецензию, хочу сказать, что само по себе новое исследование старой палеоантропологической находки на новом витке наших знаний и технологических возможностей весьма похвально, интересно, перспективно и может только приветствоваться. К сожалению, рецензируемая статья содержит целый ряд небрежностей, иногда просто нелепостей. Прежде всего это относится к таблице №1 (см. таблицу в данной рецензии). К этому можно добавить, что в таблице были перепутаны цифровые обозначения первых двух приведенных признаков - gl-la по Мартину это №3, a gl-in по Мартину - №2, а не наоборот, что точка лямбда обозначается двумя буквами, а не одной, что название серии в русскоязычной литературе - Тафоральт на конце имеет букву т, так же как один из гротов Гримальди носит устоявшееся в отечественной литературе название «Грот детей» ( а не Грот-дез-Анфан), что стоянка Мальта находится в Прибайкалье, а не в Забайкалье (Аннотация и с. 154 ) и не в Западной Сибири (с.152), что Пржедмости и Дольни Вестонице не являются восточноевропейскими стоянками (с.153). Эти ляпсусы можно было бы объяснить торопливостью (конец года, необходимость отчетности числом публикаций), если бы ....

- если бы не примитивное толкование диагностических свойств отдельных одонтологических признаков, без учета той роли, которую они играют на различных ступенях эволюционных преобразований, подробно изложенной в основополагающих статьях А.А. Зубова. В частности, о роли таких признаков, как дистальный гребень тригонида, или лопатообразность латеральных верхних резцов (например балл 2 лопатообразности зафиксирован на верхних латеральных резцах у индивидов К-18 или у французской находки из Ложери Басс, но никому и в голову не придет объяснять эту особенность восточным импульсом). 
- если бы не анонсирование широкой программы исследования, не получившего отражения в тексте статьи, или промелькнувшее в статье замечание о неметрических особенностях ориньякской серии Ла-Балозьер без ссылки на автора исследования и, т.о. создающее впечатление не столько об эрудиции авторов статьи, сколько о конкретной проделанной ими работе.

- если бы не возникал вопрос: почему авторы статьи так неуважительно относятся к читателю, просто показывая ему результат проведенных исследований, но отказывая ему в праве понять, каким образом этот результат был получен.

- $\quad$ и самое главное, если бы не пренебрежительное отношение к трудам своих коллег, А.А. Зубова, Н.И. Халдеевой, Н.В. Харламовой, занимающихся теми же проблемами и изучением тех же находок, что и авторы рецензируемой статьи, что выразилось в отсутствии ссылок на их работы и, главное, трактовке одонтологических особенностей индивида Мальта 2 «с точностью до наоборот»

И это уже не просто торопливость и небрежность. На ум приходит высказывание Г.Ф. Дебеца более 50 лет тому назад по поводу моей студенческой работы, которое я запомнила на всю жизнь: «Этот стиль «абы как» заставляет усомниться в содержании».

Кроме того, в статье явно ощущается не потребность ввести в научный оборот новый антропологический факт (отсюда и анонсирование проделанной работы, не получившей освещения в статье, и отсутствие первичных данных, и краткость описаний морфологических особенностей изучаемой находки), а явное желание подчеркнуть именно свою роль, свою значимость и свои достижения. В сочетании этого желания с вышеперечисленными ляпсусами и скороспелым выводом, основанным на явной ошибке из-за пренебрежения работами коллег-антропологов, рецензируемая статья огорчает и оставляет негативное впечатление.... Остается только удивляться, почему такой солидный журнал опубликовал подобную статью.

\section{Научная литература}

Алексеев В.П. Палеоантропология Земного шара и формирование человеческих рас. Палеолит. М.: Наука, 1978.

Герасимова М.М. Палеоантропологические находки // Н.Д. Праслов, А.Н. Рогачев (отв. ред.) Палеолит Костенковско-Боршевского р-на на Дону (1879-1979). Л.: Наука, 1984. С. 245-256.

Зубов А.А., Гохман И.И. Некоторые новые данные по верхнепалеолитической стоянке Мальта // Вестник антропологии. М.: ИЭА РАН, 2003. № 10. С. 14-23.

Зубов А.А. Палеоантропологическая родословная человека. 2-ое изд. М., ИТРК. 2019.

Gerasimova, Margarita $M$.

DOI: $10.33876 / 2311-0546 / 2021-54-2 / 373-379$

Review: Zubova, Alisa V., Moiseyev, Vyacheslav G., Kulkov Aleksandr M. and Anatoliy V. Obodovskiy. Reassessment of the cranial and dental data from the Upper Paleolithic site of Kostenki 15. Camera praehistorica 2 (5): 147-155

For citation: Gerasimova M.M. 2020. Review: Zubova, Alisa V., Moiseyev, Vyacheslav G., Kulkov Aleksandr M. and Anatoliy V. Obodovskiy. Reassessment of the cranial and dental data from the Upper Paleolithic site of Kostenki 15. Camera praehistorica 2 (5): 147-155. Herald of Anthropology (Vestnik Antropologii) 2: 373-379. 


\section{Author Info:}

Margarita M. Gerasimova - PhD, researcher, Institute of Ethnology and Anthropology, RAS (Moscow, Leninsky Pr. 32-a). E-mail: gerasimova.margarita@gmail.com

Funding: The research is published as part of the Research Plan of the Institute of Ethnology and Anthropology RAS

\section{References}

Alekseev, V.P. 1978. Paleoantropologiia Zemnogo shara i formirovanie chelovecheskikh ras. Paleolit. [Paleoanthropology of the globe and the formation of human races. Paleolithic]. Moscow: Nauka.

Gerasimova, M.M. 1984. Paleoantropologicheskie nakhodki [Paleoanthropological findings]. In Paleolit Kostenkovsko-Borshevskogo r-na na Donu (1879-1979), edited by N.D. Praslov \& A.N. Rogachev, 245-256. Leningrad: Nauka.

Zubov, A.A., and I.I. Gokhman. 2003. Nekotorye novye dannye po verkhnepaleoliticheskoi stoianke Mal'ta [Some new data on the Upper Paleolithic site of Malta]. Herald of Anthropology (Vestnik Antropologii) 10: 14-23.

Zubov, A.A. 2019. Paleoantropologicheskaia rodoslovnaia cheloveka. 2-oe izdanie [Human paleoanthropological ancestry], Second edition. Moscow: ITRK. 